\title{
On-farm deaths of dairy cows are associated with features of freestall barns
}

\author{
K. Sarjokari, ${ }^{*}{ }^{1}$ M. Hovinen, $\dagger$ L. Seppä-Lassila, $\dagger$ M. Norring, $\dagger$ T. Hurme, $\ddagger$ O. A. T. Peltoniemi, $\dagger$ T. Soveri, $\dagger$ \\ and P. J. Rajala-Schultz† \\ *Valio Ltd., Box 10, 00039 Valio, Finland \\ †Department of Production Animal Medicine, Faculty of Veterinary Medicine, University of Helsinki, Paroninkuja 20, 04920 Saarentaus, Finland \\ łEconomics and Society, Natural Resources Institute Finland (Luke), 31600 Jokioinen, Finland
}

\section{ABSTRACT}

On-farm death (OFD) of a dairy cow is always a financial loss for a farmer, and potentially a welfare issue that has to be addressed within the dairy industry. The aim of this study was to explore the associations between OFD of dairy cows, housing, and herd management in freestall barns. To achieve the goal, we followed 10,837 cows calving in 2011 in 82 herds. Data were gathered with observations and a structured interview during farm visits and from a national dairy herd improvement database. The hazard of OFD was modeled with a shared frailty survival model, with SAS 9.3 PHREG procedure (SAS Institute Inc., Cary, NC). The study population was 58\% Ayrshire and $42 \%$ Holstein cows. The median herd size and mean milk yield in the study herds were 116 cows and $9,151 \mathrm{~kg}$ of milk per cow per year. The overall probability of OFD was $6.0 \% ; 1.8 \%$ of the cows died unassisted and $4.2 \%$ were euthanized. Variation in OFD percentage between individual herds was large, from 0 to $16 \%$, accounting for 0 to $58 \%$ of all removals in the herds. Keeping close-up dry cows in their own group was associated with higher hazard of OFD [hazard ratio $(\mathrm{HR})=1.37$ ] compared with keeping them in the same pen with far-off dry cows. Higher hazard on OFD was observed when barns had only one kind of calving pen; single $(\mathrm{HR}=2.09)$ or group pens $(\mathrm{HR}=1.72)$, compared with having both of those types. The hazard of OFD was lower if the whole herd was housed in barns or pens that had only 1 type of feed barrier at the feed bunk, namely post-and-rail $(\mathrm{HR}=0.51)$ or a type with barriers between the cow's heads $(\mathrm{HR}=0.49)$, compared with having 2 types. Lower OFD hazard was observed with wider than 340 $\mathrm{cm}$ of walking alley next to the feeding table ( $\mathrm{HR}=$ 0.75 ), and with housing a whole herd in pens with only

Received June 30, 2017.

Accepted February 22, 2018.

${ }^{1}$ Corresponding author: kristiina.sarjokari@valio.fi
1 type of walking alley surface, specifically slatted (HR $=0.53)$ or solid $(\mathrm{HR}=0.48)$, compared with having both types. The hazard of OFD was higher with stalls wider than $120 \mathrm{~cm}(\mathrm{HR}=1.38)$ compared with narrower stalls. The hazard of OFD was also associated with breed, parity, and calving season. This study identified many factors that contribute to the incidence of OFD of dairy cows. The solutions for reducing on-farm mortality include housing, management, and breeding choices that are most probably herd specific.

Key words: dairy cow, adult cattle mortality, death, euthanasia

\section{INTRODUCTION}

On-farm death (OFD) of a dairy cow is always a loss for a dairy producer. It occurs mostly in early lactation (Hertl et al., 2011; Alvåsen et al., 2014; Shahid et al., 2015), leading to a markedly lower than potential profit for the cow. Often, veterinary and medicinal costs are incurred before death or euthanasia, the sale price of the carcass is lost, and the cadaver has to be destroyed, which all contribute to the total costs. In addition, a lactating replacement animal is usually not available immediately, and some of the production potential of the farm is lost. Many of the cows that die or need to be euthanized on farm would not have been yet culled voluntarily; therefore, the farmer loses some of the herd's genetic potential.

Dairy herds are increasing in size as a reflection of the greater demands for efficiency. Intensification of production has been suggested to affect cow mortality (Nørgaard et al., 1999); it has been reported being higher in larger herds (Raboisson et al., 2011; Alvåsen et al., 2012, 2014) and in herds with a higher cow to employee ratio (McConnel et al., 2015). High on-farm mortality is an ethical issue of public concern and a potential indicator of poor cow welfare (de Vries et al., 2011; Nielsen et al., 2014).

On-farm death has increased in many countries during the last decades: from 2 to $3.5 \%$ in Denmark during 1990 to 2001 (Thomsen et al., 2004), from 2 to $4.6 \%$ 
during 1995 to 2005 in the United States (Miller et al., 2008), and from 5.1 to 6.6 events per 100 cow-years in Sweden during 2002 to 2010 (Alvåsen et al., 2012). In Finland, at herd level, a median of $5 \%$ of the dairy cows died on farm in 2016. The percentage was slightly higher, 6\%, for herds with 100 or more cows (Finnish DHI database). Other authors have reported similar mortalities, at $6.1 \%$ in Sweden (Alvåsen et al., 2014) and 6.8 in the United States (Shahid et al., 2015).

Previous studies have reported several cow- and herd-level risk factors (Alvåsen et al., 2012; Maia et al., 2014; Shahid et al., 2015), seasonal effects (Stull et al., 2008; Vitali et al., 2009, 2015), and diseases (McConnel et al., 2008; Alvåsen et al., 2014) associated with onfarm mortality of dairy cows. Ten years ago, a review reported 19 studies on this topic (Thomsen and Houe, 2006); however, we could not find any published studies that focused especially on the associations of housing on OFD. We hypothesized that management factors in freestall barns would have an effect on OFD. Therefore, the goal of our study was to identify those factors that are directly related to housing and have the potential to contribute to better cow survival.

\section{MATERIALS AND METHODS}

\section{Sampling, Inclusion, and Exclusion Criteria}

Study herds were selected from the herds in the Finnish DHI database, operated by ProAgria Agricultural Data Processing Centre (http://www.mloy.fi), previously described and used by other authors (Gröhn et al., 1984; Olsson et al., 2001; Kyntäjä and Niskanen, 2007). All herds in the database with a mean herd size greater than 80 in $2010(\mathrm{n}=184)$ were invited to participate in the project.

A total of 82 herds volunteered and met the inclusion criteria. The criteria were (1) using a conventional production system (not organic), (2) housing in an insulated freestall barn at least for $2 \mathrm{yr}$ before the time of the farm visit, and continuing to be housed there during the survey, and (3) herds with an automatic milking system used at least 2 milking robots with a reasonable stocking capacity (at least 45 cows per robot in 2010).

The study herds were visited once between January and April in 2012. The herd owners were interviewed about the herd management with a predesigned questionnaire and barns and animals were observed by 1 of the 3 veterinarians that were equally trained for the visits, with oral and written instructions and 3 training herd visits. The cow-level data on breed, parity, calving date, milk yield, removal method, and reason were received from DHI database.

\section{Statistical Analysis}

Descriptive statistics were first calculated for the data. The percentages were calculated based on the total number of study cows 10,907. Cows of breeds other than Ayrshire or Holstein were then excluded $(n=69)$, and the hazard of OFD was statistically modeled with a survival model, where clustering of cows within herds was taken into account by animals in the same herd sharing a random, frailty effect. In the analysis, a total of 10,837 cows were followed for 305 d, starting from their first calving day of the year 2011.

A shared frailty survival model is an extension of the standard semiparametric Cox model. The model can be written as

$$
\lambda(t)=Z_{i} \lambda_{0 j}(t) e^{\beta^{T} X_{i j}}
$$

where $\lambda_{0 j}(t) e^{\beta^{T} X_{i j}}$ is the same as the model for standard semiparametric Cox model $\left[\lambda_{0 j}(t)\right.$ are the baseline hazard functions and $\beta$ is a vector of fixed effect parameters to be estimated] and the frailties $Z_{i}$ are assumed to be identically and independently distributed random variables with a common density function (Wienke, 2011).

The study period was between January 1, 2011, and October 31, 2012. Only 1 lactation period per cow was included. The modeled outcome was time from calving until unassisted death or euthanasia on farm. The observations were censored if a cow left the herd for any other removal reason or if the study period ended before the outcome of interest occurred. Noncompleted lactations were also included, which is possible in using survival analysis.

The potential explanatory variables were grouped into cow-level characteristics and herd-level attributes or practices. The first step of the modeling process was univariable screening, and cow-level features were introduced into a model individually in addition to the herd frailty. Next, cow-level variables with $P<0.25$ in the univariable models were added into a joint model, and variables with $P>0.1$ were removed one by one from this model. The examined cow-level characteristics were breed, animal born at farm or bought, age at arrival to herd, age at first calving, parity of the study lactation, calving season, and milk yield relative to time from calving.

The herd-level variables were then added individually to the model built during the previous step,. The herdlevel variables with $P<0.25$ in univariable screening were then added in the model jointly and the model was again reduced until all variables were statistically significant $(P \leq 0.05)$. 
Altogether, 8 cow-level and 39 herd-level housing and management attributes were studied (Supplemental Tables S1-S3; https://doi.org/10.3168/jds.2017 -13420). Potential collinearity between the variables was examined by visual examination of frequency tables and with 2-way chi-squared tests with no indications of collinearity.

The associations between OFD and herd size, stocking density, square meters per lactating cow in a pen, type of ventilation, milking and feeding systems in use, feeding space per cow and feed rack type, the properties of walking and lying surfaces, access to pasture or outdoor exercise area, and the time that the cows had been in the barns were explored. Likewise, associations between OFD and grouping strategies of pregnant heifers, dry cows, and lactating cows in the barn, calving pen type, time of moving the cow into a calving pen before calving, time spent in the calving pen, and the change in the walking and lying area properties when a heifer moves from its initial group to a group of lactating cows were studied.

After finding the model with main effects, all meaningful interactions were tested in the model. Because diseases usually precede OFD, but often act as intervening variables between the effects of management and housing and OFD (Dohoo et al., 2009), they were not included in the model (the descriptive analysis and associations between OFD and of the most important diseases will be published separately). The statistical models described above were fitted using the PHREG procedure of SAS 9.3 (SAS Institute Inc., Cary, NC). Gamma distribution was used for the frailties. The assumptions of the model include the proportional hazards assumption and the assumption of linearity for continuous explanatory variables. These assumptions were examined using graphs and tests obtained from the PHREG procedure. Univariate survival plots were also plotted using the LIFETEST procedure in SAS.

\section{RESULTS}

\section{Cow and Herd Properties}

Of the cows of the study herds, $58 \%(\mathrm{n}=6,303)$ were Ayrshire and $42 \%(\mathrm{n}=4,535)$ were Holstein; less than $1 \%(\mathrm{n}=69)$ were other breeds (mostly Finn cattle). All parities were equally represented in the herds; 3,789 first, 3,174 second, and 3,874 of parity $>2$ cows (mean $=2.28, \mathrm{SD}=1.33$; range $=1$ to 12 , median $=2$, data on parity was missing for 1 cow). The cows calved evenly throughout the year, with 3,471 calvings $(32 \%)$ from January to April, 3,696 (34\%) from May to August, and 3,740 (34\%) from September to December.
The median herd size on the day of the herd visit was 116 cows (range $=73$ to 326 ), and mean milk yield $9,151 \mathrm{~kg}(\mathrm{SD}=870)$ per cow per year. Most study herds $(\mathrm{n}=79 ; 96 \%)$ had both Ayrshire and Holstein cows; only 3 herds had just 1 breed. Of the facilities in use, $24(29 \%)$ were relatively new and had been in use for 2 to 4 yr. Eleven barns (13\%) had been in use for 4 to $10 \mathrm{yr}, 30(37 \%)$ for more than $10 \mathrm{yr}$, and $17(21 \%)$ had undergone multiple expansions. Most barns ( $\mathrm{n}=$ $48 ; 59 \%)$ had natural ventilation, $38 \%(\mathrm{n}=31)$ had mechanical ventilation, and 3 herds (4\%) had both types of ventilation systems in use. The majority of the herds ( $\mathrm{n}=50 ; 61 \%$ ) were milked in a conventional milking parlor and the rest of the farms $(\mathrm{n}=32 ; 39 \%)$ had an automatic milking system. The stocking density was on average $95 \%(\mathrm{SD}=11)$ in the groups of lactating cows.

\section{The Incidence of OFD and Reported Reasons}

In total, $22.8 \%(\mathrm{n}=2,469)$ of the study cows left the herd within $305 \mathrm{~d}$ after calving, and OFD $(\mathrm{n}=648)$ accounted for $26.2 \%$ of all removals. The overall incidence of a cow experiencing OFD was $6.0 \%$, with $3.4,4.5$, and $9.6 \%$ for parity 1,2 , and $3+$ cows, respectively. A total of $1.8 \%(\mathrm{n}=195)$ of the cows died unassisted and $4.2 \%$ ( $\mathrm{n}=453)$ were euthanized. The rest of the culled cows $(\mathrm{n}=1,821)$ were sent to a slaughterhouse.

The median time from calving to OFD was $34 \mathrm{~d}$ (ranged $=0$ to 305 ), at 44, 46, and $26 \mathrm{~d}$ for parity 1,2 , and $3+$ cows, respectively. Most cows that died on farm did so within the very first DIM, with cumulative percentages being $10.2 \%$ by d $2,28.1 \%$ by d $10,48.2 \%$ by d 30 , and $63.0 \%$ by d 60 . Death on farm was the most common type of removal in early lactation (Figure 1), accounting for $90.4 \%$ of the removals from the herd during the first $2 \mathrm{~d}, 70.0 \%$ for the first $10 \mathrm{~d}$, and $55.7 \%$ for the first $30 \mathrm{~d}$ postpartum.

Large variation existed in the percentages of OFD between individual herds (Figure 2), ranging from 0.0 to $15.7 \%$ (median $=5.9 \%$ ). At herd level, OFD accounted for 0.0 to $57.9 \%$ (median $=24.9 \%$ ) of all the removals during the $305 \mathrm{~d}$ following parturition. The overall culling percentage in the herds varied from 11.6 to $51.6 \%$ (median $=31.8$ ).

The most frequently reported reasons by farmers for OFD were feet and claw disorders $(\mathrm{n}=81 ; 13 \%)$, mastitis $(\mathrm{n}=77 ; 12 \%)$, gastrointestinal disease $(\mathrm{n}=75$; $12 \%)$, accident $(\mathrm{n}=73 ; 11 \%)$, milk fever $(\mathrm{n}=54 ; 8 \%)$, and calving difficulty $(\mathrm{n}=41 ; 6 \%)$, illustrated by parity and type of death in Figure 3. The codes unknown, other disease, and other reason accounted for $34 \%$ of the reported reasons $(\mathrm{n}=219)$. 


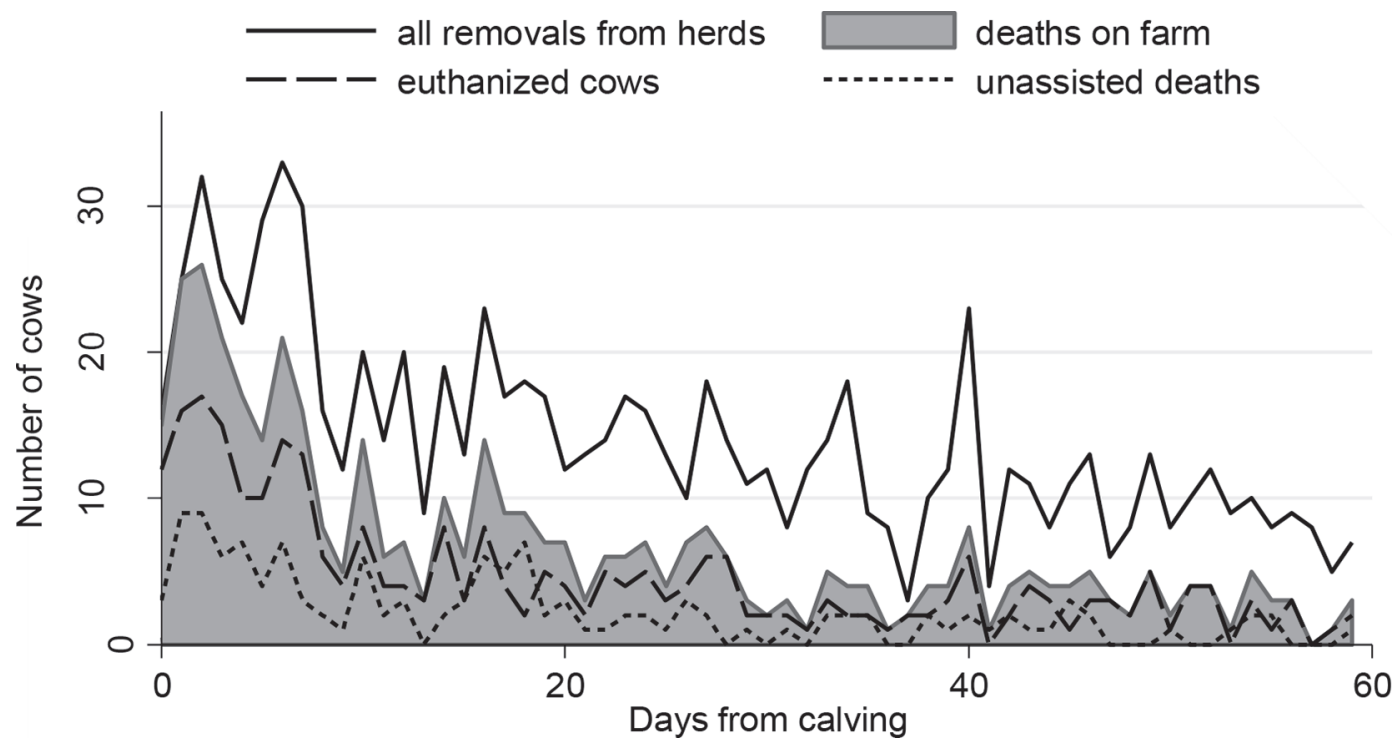

Figure 1. The number of culled cows per days from calving and the means of their removal from the herd. The total number of the study cows is 10,837; only the first $60 \mathrm{~d}$ are shown in the figure.

\section{Associations of Housing and Management Practices on the Hazard of OFD}

The hazard of OFD was significantly higher if the close-up dry cows were kept in their own group compared with keeping them with other dry cows. Having both group and single calving pens in a barn was beneficial compared with having only 1 of the 2 types of pens (Table 1).

Feed barrier type was significantly associated with OFD. The hazard of OFD was lower if the herd was housed in barns or pens with a single type for the whole herd, compared with having 2 types of feed barriers. The OFD hazard was lower if the width of the walking alley next to the feed rack was wider and if the whole herd was housed in barns and pens with only 1 type of walking alley surface, slatted or solid, compared with having 2 types floors. The odds of OFD were higher if the width of the stalls for lactating cows was $120 \mathrm{~cm}$ or wider compared with narrower stalls.

Breed, parity, and calving season were significant cow-level variables in the model. Holstein cows had a greater hazard of dying on farm than Ayrshire cows, and the hazard increased with parity. Calving between September to December decreased the hazard of OFD compared with other calving seasons.

\section{DISCUSSION}

\section{Incidence and Reasons for OFD}

On-farm mortality leads to suffering of the cows, to involuntary and too early removal of the cow from a herd, and to financial losses for dairy producers; thus, it should be kept low, ideally below 3 to $5 \%$. However, OFD is a common reason for a dairy cow to leave a herd. On average, every fourth culled cow was removed this way in the study population. Therefore, it is quite surprising that only a few published scientific papers specifically describe the associations between OFD and housing.

The overall probability of OFD in our study was quite similar to recent Swedish and US studies (Alvåsen et al., 2014; Shahid et al., 2015). It would not be meaningful to compare the incidence of OFD to much older studies, because mortality seems to have increased during the last decades (Thomsen et al., 2004; Miller et al., 2008; Alvåsen et al., 2012).

The large between-herd variation in the OFD of dairy cows is partly due to differences in the risk factors for diseases and accidents, and probably partly due to different attitudes, beliefs, and skills of the producers on solving herd problems (Vaarst and Sørensen, 2009). Some producers treat sick cows more intensively and try to keep as many cows as possible live to be slaughtered after being ill, whereas others may find euthanasia a more humane or easier option.

Death, in general, and dying unassisted especially, causes suffering for a cow (Nielsen et al., 2014). Of the cows that died on farm in our study population, $70 \%$ were euthanized and 30\% died unassisted. This differed from the findings of an earlier Danish and a recent Italian study, where 55 or $58 \%$ were euthanized and 45 or $42 \%$ of the cows died unassisted, respectively (Thomsen et al., 2004; Fusi et al., 2017). 


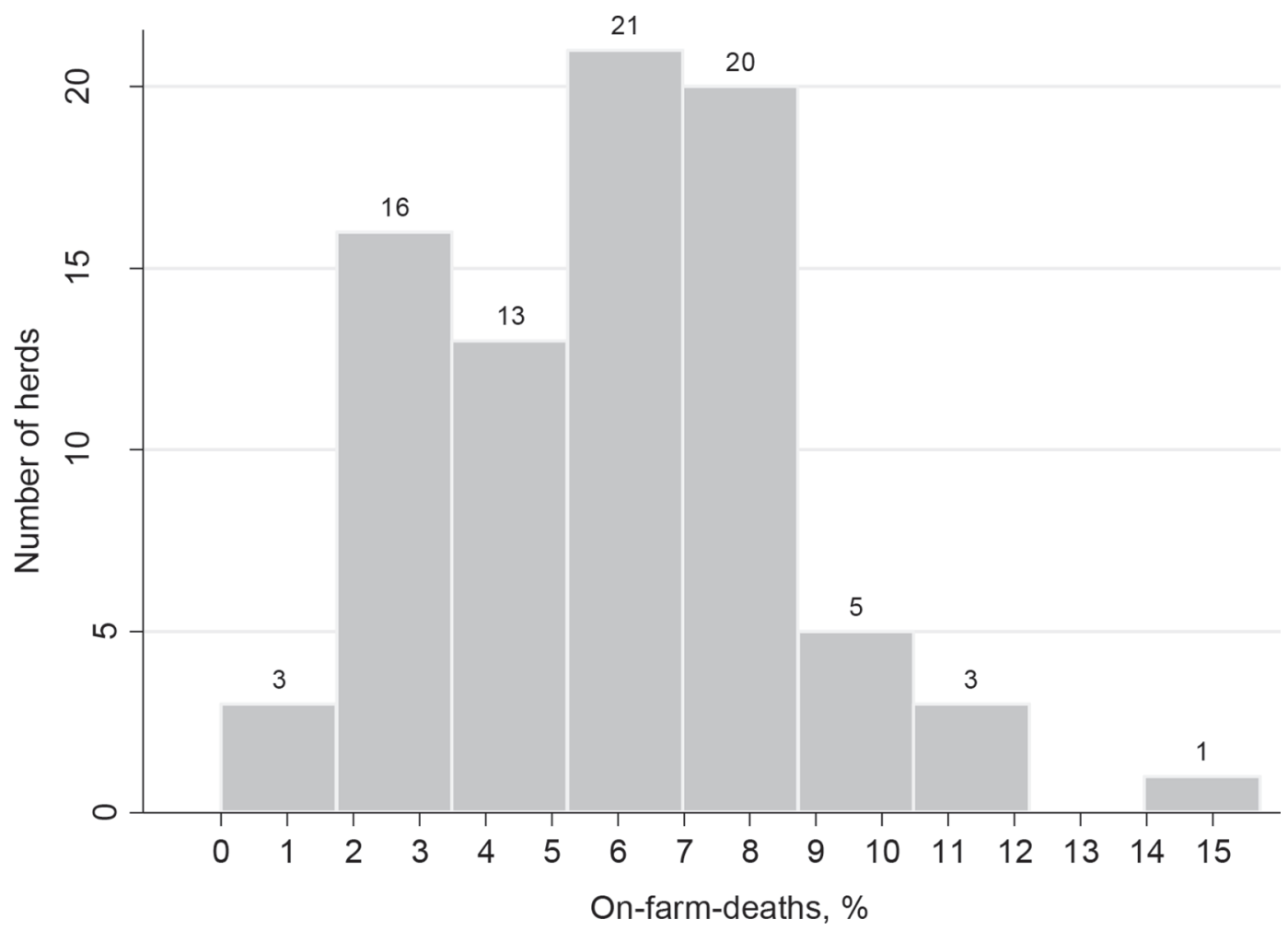

Figure 2. Herd-level incidence of on-farm deaths in the study herds. Cows that calved in 2011 are included.
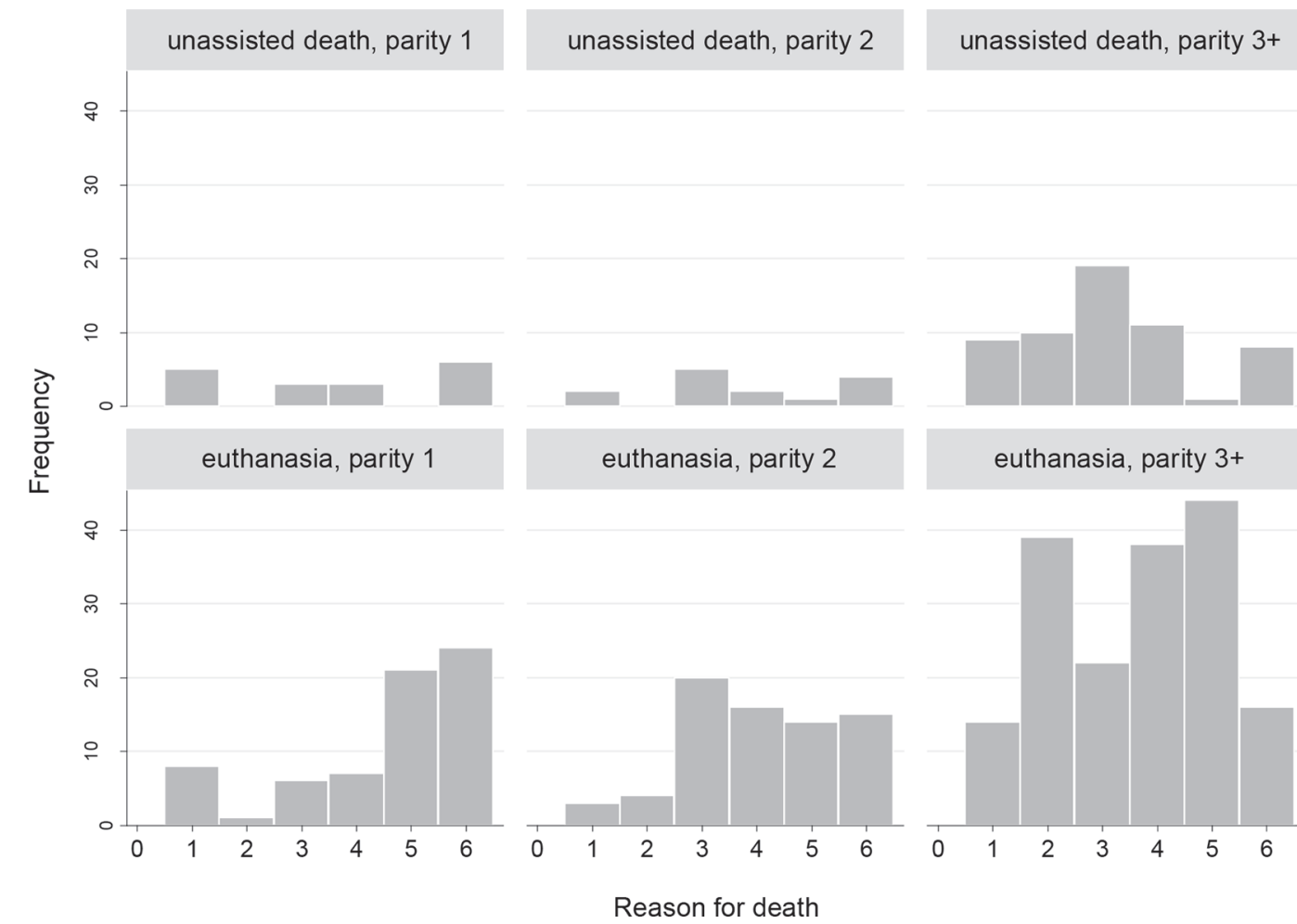

euthanasia, parity $3+$

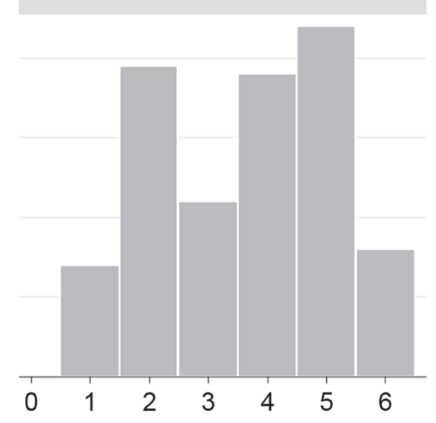

Figure 3. The most frequently reported reasons of death of the study cows by parity and the means of death. $1=$ calving difficulty; $2=$ milk fever; $3=$ alimentary tract disease; $4=$ mastitis; $5=$ foot or claw disease; $6=$ accident. 
Accidents, calving difficulties, and feet and claw diseases dominated the reported reasons for OFD of first-parity cows in our study. Milk fever, mastitis, and foot and claw diseases were the most often reported reasons for OFD for parity $3+$ cows in our data. Even though lameness is not any bigger problem in Finland compared with other countries (Espejo et al., 2006; Dippel et al., 2009; Sarjokari et al., 2013), foot and claw diseases were the most frequently reported reason for OFD. This is most possibly because in Finland (within EU) it is not legal to send severely lame cow to a slaughterhouse. Therefore, very severe cases of, for example, interdigital phlegmon, digital dermatitis, and joint infections lead to euthanasia on farm.

The recorded reasons for death or euthanasia are usually based on a clinical diagnosis and reasoning made on farm by a vet or a farmer; the conclusion made is often not in agreement with necropsy findings (McConnel et al., 2009; Pinedo et al., 2010; Thomsen et al., 2012). Despite that, we should not overlook the potential usefulness of the records as an aid for risk factor analysis and making strategies for reducing OFD, because the most commonly reported distinct reasons, such as ac- cidents, calving difficulties, milk fever, mastitis, and feet and claw diseases, are relatively easy to diagnose. They also are very frequently reported reasons for OFD by other authors as well (Thomsen et al., 2004, 2012; Alvåsen et al., 2014; Fusi et al., 2017).

\section{Dry Cow Management and Calving Pens}

In the current study, keeping the close-up cows in the same pen with far-off dry cows, or even with lactating cows, was associated with lower hazard of OFD compared with keeping them in their own group before calving. Having 2 groups would lead to more group changes, and regrouping is physically and socially stressful for a cow, especially for subordinate individuals. Regrouping increases agonistic interactions (Kondo and Hurnik, 1990; Schirmann et al., 2011) and causes a drop in DMI and rumination time in prefresh period (Schirmann et al., 2011), predisposing cows to subclinical and clinical metabolic diseases, which further predispose to alimentary or infectious diseases such as displaced abomasum and metritis, and to culling or death within the first 30 DIM (reviewed by Ospina

Table 1. The associations of the statistically significant factors on the hazard of on-farm death of 10,837 cows in 82 herds (distribution of cowand herd-level observations between the groups in parentheses)

\begin{tabular}{|c|c|c|c|c|}
\hline Parameter & Group & $\mathrm{HR}^{1}$ & $95 \% \mathrm{CI}$ & $P$-value ${ }^{2}$ \\
\hline \multirow[t]{4}{*}{ Grouping of the close-up dry cows } & With other dry cows (31 herds: 4,118 cows) & Reference & & $<0.01$ \\
\hline & In their own group ( 20 herds: 2,746 cows) & 1.37 & $1.06-1.76$ & $<0.01$ \\
\hline & In a group calving pen ( 14 herds: 1,908 cows) & 1.28 & $0.99-1.65$ & 0.06 \\
\hline & With lactating cows ( 17 herds: 2,065 cows) & 0.78 & $0.61-0.99$ & 0.04 \\
\hline \multirow[t]{4}{*}{ Type of the calving pen } & Both group and single pens ( 4 herds: 581 cows) & Reference & & $<0.01$ \\
\hline & Group pens only ( 48 herds: 6,478 cows) & 1.72 & $1.09-2.69$ & 0.02 \\
\hline & Single pens only ( 26 herds: 3,140 cows) & 2.09 & $1.32-3.31$ & $<0.01$ \\
\hline & No calving pens ( 4 herds: 638 cows) & 1.50 & $0.82-2.74$ & 0.20 \\
\hline \multirow[t]{3}{*}{ Type of the feed barrier } & Both two types (6 herds: 897 cows) & Reference & & $<0.001$ \\
\hline & Post-and-rail (60 herds: 7,904 cows) & 0.51 & $0.36-0.71$ & $<0.0001$ \\
\hline & Barriers between cows ( 16 herds: 2,036 cows) & 0.49 & $0.35-0.70$ & $<0.0001$ \\
\hline \multirow{3}{*}{$\begin{array}{l}\text { Width of the walking alley next } \\
\text { to the feed bunk }\end{array}$} & $<340 \mathrm{~cm}$ (32 herds: 4,074 cows) & Reference & & $<0.01$ \\
\hline & $340-370 \mathrm{~cm}$ ( 24 herds: 2,825 cows) & 0.71 & $0.57-0.88$ & $<0.0001$ \\
\hline & $>370 \mathrm{~cm}(26$ herds: 3,938 cows $)$ & 0.75 & $0.61-0.92$ & $<0.01$ \\
\hline \multirow[t]{3}{*}{ Type of the walking alley surface } & Both solid and slatted floors ( 3 herds: 341 cows) & Reference & & $<0.01$ \\
\hline & Solid concrete floors only ( 35 herds: 4,359 cows) & 0.48 & $0.33-0.71$ & $<0.001$ \\
\hline & Slatted concrete floors only (44 herds: 6,137 cows) & 0.53 & $0.36-0.78$ & $<0.01$ \\
\hline \multirow[t]{3}{*}{ Width of the stalls ${ }^{3}$} & $<120 \mathrm{~cm}$ (24 herds: 3,344 cows) & Reference & & $<0.01$ \\
\hline & $120 \mathrm{~cm}$ (39 herds: 4,888 cows $)$ & 1.38 & $1.11-1.72$ & $<0.01$ \\
\hline & $>120 \mathrm{~cm}$ (19 herds: 2,605 cows $)$ & 1.51 & $1.17-1.94$ & $<0.01$ \\
\hline \multirow[t]{2}{*}{ Breed } & Ayrshire (6,303 cows) & Reference & & $<0.001$ \\
\hline & Holstein (4,534 cows) & 1.34 & $1.14-1.57$ & $<0.001$ \\
\hline \multirow[t]{3}{*}{ Parity } & 1 st $(3,789$ cows $)$ & Reference & & $<0.0001$ \\
\hline & 2 nd $(3,174$ cows $)$ & 1.37 & $1.08-1.75$ & $<0.01$ \\
\hline & $3+(3,874$ cows $)$ & 3.30 & $2.70-4.04$ & $<0.0001$ \\
\hline \multirow[t]{3}{*}{ Calving season } & September-December (3,711 cows) & Reference & & 0.03 \\
\hline & January-April (3,447 cows) & 1.25 & $1.04-1.52$ & 0.02 \\
\hline & May-August (3,679 cows) & 1.25 & $1.03-1.52$ & 0.02 \\
\hline
\end{tabular}

\footnotetext{
${ }^{1}$ Hazard ratio.

${ }^{2} P$-values of comparisons of the group with the baseline group. The bold $P$-values represent the significance for the entire variable.

${ }^{3}$ Mean of different pens, weighted by the number of cows in the pen.
} 
et al., 2013). In addition, regrouping led to prolonged standing and shortened resting times predisposing to lameness (reviewed by Cook and Nordlund, 2004).

In the present study, having both group and single calving pens for a herd was associated with lower hazard of OFD compared with having only 1 type of pens. This could be explained by a better opportunity to manage and monitor the calvings in a herd and by offering a cow a peaceful calving environment. Cows have been shown to seek isolation at calving (Proudfoot et al., 2014), and correct timing when moving the cow to a calving pen enhances calving ease (Proudfoot et al., 2013). Early signs of dystocia can be noticed even $24 \mathrm{~h}$ before calving (Proudfoot et al., 2009a), and close monitoring over calvings and assisting cows that need help can reduce OFD due to calving problems. Likewise, the attitude and skills of the farmer may have an effect on intensity of observing calvings and on choosing calving pen types.

\section{Feed Bunk, Walking Alleys, and Stalls}

Most agonistic behavior takes place at the feed bunk (Miller and Woodgush, 1991). Competition at the feed bunk is especially problematic for subordinate cows, leading to displacements, prolonged standing times on walking alleys, less possibilities for eating during the most popular eating times (Olofsson, 1999; DeVries et al., 2004; Huzzey et al., 2006; Proudfoot et al., 2009b), and potentially to eating a somewhat different ratio, leftover from dominant cows (DeVries et al., 2005). Therefore, restlessness at the feed bunk can predispose cows to metabolic and claw diseases.

In our study, the hazard of OFD was significantly lower with a feed bunk with 1 type of feed barrier. Having both post-and-rails and some types of barriers between the cow's heads doubled the hazard of OFD. Previous studies have reported increased feeding activity, less agonistic behaviors, and less lameness with headlocks at the feed bunk (Huzzey et al., 2006; DeVries and von Keyserlingk, 2006; Sarjokari et al., 2013) or with more feeding space (DeVries et al., 2004; Huzzey et al., 2006).

Having 2 types of feed barrier designs may lead to longer standing times at the bunk or to lower DMI. Cows need time to learn to use headlocks (reviewed by Cook and Nordlund, 2004), or they may favor postand-rail if there are 2 types of barriers in the same pen (Huzzey et al., 2006).

Having 2 different types of walking alley surfaces in pens for lactating cows doubled the hazard of OFD in the current study. As one of the floor types is often more slippery than the other (Sarjokari et al., 2013), and the cows do not always notice moving from one to another, 2 types probably increase claw trauma and other accidents. Similarly, cows have shown to change their gait on different floors, walking slower and with shorter steps on slats (Telezhenko and Bergsten, 2005). This finding might also be related to inadequate lightning.

The hazard of OFD was lower in our study when the width of the walking alley next to the feed rack was wider than $340 \mathrm{~cm}$. This finding can be explained by reduced competition over feed and water (Kondo et al., 1989; Miller and Woodgush, 1991), increased daily lying time (Solano et al., 2016), and reduced risk for lameness (Sarjokari et al., 2013).

In the current study, the hazard of OFD was smaller if the width of the stalls for cows was less than 120 $\mathrm{cm}$ compared with wider stalls. This finding should be interpreted with caution, as stall adjustment includes many measures that interact with each other in a complex way (e.g., stall length and width, placement of post and neck rails, and brisket board). Sarjokari et al. (2013) pointed out that many farmers adjust neck and front rails incorrectly, and improper stall design has been shown to reduce resting and increase standing times and to predispose cows to lameness (reviewed by Cook and Nordlund, 2009).

In the current study herds, cows of different sizes were housed in same pens; usually both Ayrshires and Holsteins and first and higher parities. Therefore, it can be assumed that compromises in the adjustment of stalls occurred. Too wide of a stall in relation to the size of a cow, especially if combined with too short of a stall or improper adjustment of a brisket board or a neck rail can lead to diagonal standing and lying in stalls (reviewed by Cook and Nordlund, 2004). This, in turn, results in dirty cows and hock lesions which may increase the risk for mastitis and joint infections.

\section{Breed and Parity}

Holsteins' hazard of OFD was greater than Ayrshires in our study. Higher mortality of Holstein cows, compared with other breeds has also been observed in other studies (Alvåsen et al., 2012; Maia et al., 2014; Shahid et al., 2015). Part of this phenomenon might be due to genetics (Miller et al., 2008; Dechow et al., 2012; Maia et al., 2014) or due to usually higher milk yield of Holstein cows. Another possible explanation is that Holsteins are generally bigger and heavier than many other dairy breeds, therefore suffering more easily from suboptimal freestall environments (e.g., too short, narrow, or incorrectly adjusted stalls; predisposing for example to claw diseases), especially in herds with 2 or more breeds. This reasoning is supported by Alvåsen et al. (2014), who observed higher odds for mortality 
in herds with mixed breeds. The hazard of OFD being greater for higher parities in the present study population was in agreement with earlier studies (Thomsen et al., 2004; McConnel et al., 2009; Alvåsen et al., 2014).

\section{Calving Season}

Calving in September to December was associated with a lower hazard of OFD compared with calving in January to August in our study. In 2011 in Finland, the winter was very cold, with unusually large and quick temperature changes, and the summer was exceptionally warm with long heat waves (http://blogi.foreca.fi/ 2012/01/saavuosi-2011/); these weather changes may have affected the cows. The relationship between cow mortality and daily temperature has shown to be Ushaped (Stull et al., 2008), and the effect of weather conditions on mortality has been shown to depend on temperature, humidity, duration and time of the heat wave, and on age of the cows (Vitali et al., 2009, 2015). Improper cooling or excess moisture can predispose cows to infectious diseases and trigger disease severity, potentially increasing the likelihood of OFD (Hahn, 1999; Silanikove, 2000; Kadzere et al., 2002).

The seasonality of OFD in our study was in agreement with some other authors (Miller et al., 2008; Pinedo et al., 2010; Raboisson et al., 2011; Alvåsen et al., 2012). Hertl et al. (2011) reported no effect of season among parity 1 cows, but higher likelihood for multiparous cows to die in spring and summer. Alvåsen et al. (2014) reported higher hazard for OFD for cows that calved during January to April compared with other seasons. Possible reasons for deviant findings are different definitions for seasons (e.g., Vitali et al., 2009; Alvåsen et al., 2014) and changes in the weather conditions between different study years and countries.

\section{Limitations of the Study}

The results of our study can be extrapolated only to herds housed in freestall bars with cubicles and with relatively similar herd sizes, breeds, and milk yields. The study period was relatively short, and we probably could have gained more information by adding several study years. However, in the final model we found many significant variables associated with OFD with no collinearity between them. This being so, our study increased our knowledge on OFD of dairy cows.

\section{CONCLUSIONS}

This study identified animal- and housing-related factors that contributed to the incidence of on-farm deaths of dairy cows in freestall barns. Avoiding un- necessary group changes during the dry period and eliminating unnecessary variations in barn facilities in lactating cow pens seem potential options for reducing OFD. In addition, having both group and single calving pens, providing enough space at the walking alleys, and offering cows a feed bunk with barriers between cow heads may help improving cow survival and longevity.

\section{ACKNOWLEDGMENTS}

We gratefully acknowledge the dairy farmers participating this study. We also thank all the researchers of LYTO2-Project for good cooperation, and especially Mira Tenhunen, Tarja Kujala, and Mari Utriainen, who were postgraduate students, and Marika Virtanen, who was a graduate student at the University of Helsinki, for their help in collecting and inputting data. This study was funded by the Ministry of Agriculture and Forestry in Finland, Walter Ehrström's foundation, Valio Ltd., and Finnish Veterinary Foundation (all located in Helsinki, Finland).

\section{REFERENCES}

Alvåsen, K., M. Jansson Mork, I. R. Dohoo, C. H. Sandgren, P. T. Thomsen, and U. Emanuelson. 2014. Risk factors associated with on-farm mortality in Swedish dairy cows. Prev. Vet. Med. 117:110 120.

Alvåsen, K., M. Jansson Mork, C. Hallen Sandgren, P. T. Thomsen, and U. Emanuelson. 2012. Herd-level risk factors associated with cow mortality in Swedish dairy herds. J. Dairy Sci. 95:4352-4362.

Cook, N. B., and K. V. Nordlund. 2004. Behavioral needs of the transition cow and considerations for special needs facility design. Vet. Clin. North Am. Food Anim. Pract. 20:495-520.

Cook, N. B., and K. V. Nordlund. 2009. The influence of the environment on dairy cow behavior, claw health and herd lameness dynamics. Vet. J. 179:360-369.

de Vries, M., E. A. M. Bokkers, T. Dijkstra, G. van Schaik, and I. J. M. de Boer. 2011. Invited review: Associations between variables of routine herd data and dairy cattle welfare indicators. J. Dairy Sci. 94:3213-3228.

Dechow, C. D., R. C. Goodling, and S. P. Rhode. 2012. The effect of sire selection on cow mortality and early lactation culling in adverse and favorable cow survival environments. Prev. Vet. Med. 103:228-233.

DeVries, T. J., M. A. von Keyserlingk, and K. A. Beauchemin. 2005. Frequency of feed delivery affects the behavior of lactating dairy cows. J. Dairy Sci. 88:3553-3562.

DeVries, T. J., and M. A. G. von Keyserlingk. 2006. Feed stalls affect the social and feeding behavior of lactating dairy cows. J. Dairy Sci. 89:3522-3531.

DeVries, T. J., M. A. G. von Keyserlingk, and D. M. Weary. 2004. Effect of feeding space on the inter-cow distance, aggression, and feeding behavior of free-stall housed lactating dairy cows. J. Dairy Sci. 87:1432-1438.

Dippel, S., M. Dolezal, C. Brenninkmeyer, J. Brinkmann, S. March, U. Knierim, and C. Winckler. 2009. Risk factors for lameness in freestall-housed dairy cows across two breeds, farming systems, and countries. J. Dairy Sci. 92:5476-5486.

Dohoo, I. R., W. Martin, and H. Stryhn. 2009. Veterinary Epidemiologic Research. 2nd ed. VER Inc., Charlottetown, Canada.

Espejo, L. A., M. I. Endres, and J. A. Salfer. 2006. Prevalence of lameness in high-producing Holstein cows housed in freestall barns in Minnesota. J. Dairy Sci. 89:3052-3058. 
Fusi, F., A. Angelucci, V. Lorenzi, L. Bolzoni, and L. Bertocchi. 2017. Assessing circumstances and causes of dairy cow death in Italian dairy farms through a veterinary practice survey (2013-2014). Prev. Vet. Med. 137:105-108.

Gröhn, Y., J. R. Thompson, and M. L. Bruss. 1984. Epidemiology and genetic basis of ketosis in Finnish Ayrshire cattle. Prev. Vet. Med. 3:65-77.

Hahn, G. L. 1999. Dynamic responses of cattle to thermal heat loads. J. Anim. Sci. 77(Suppl 2):10-20.

Hertl, J. A., Y. H. Schukken, D. Bar, G. J. Bennett, R. N. Gonzalez, B. J. Rauch, F. L. Welcome, L. W. Tauer, and Y. T. Gröhn. 2011. The effect of recurrent episodes of clinical mastitis caused by gram-positive and gram-negative bacteria and other organisms on mortality and culling in Holstein dairy cows. J. Dairy Sci. 94:4863-4877.

Huzzey, J. M., T. J. DeVries, P. Valois, and M. A. G. von Keyserlingk. 2006. Stocking density and feed barrier design affect the feeding and social behavior of dairy cattle. J. Dairy Sci. 89:126-133.

Kadzere, C. T., M. R. Murphy, N. Silanikove, and E. Maltz. 2002. Heat stress in lactating dairy cows: A review. Livest. Prod. Sci. 77:59-91

Kondo, S., and J. F. Hurnik. 1990. Stabilization of social hierarchy in dairy cows. Appl. Anim. Behav. Sci. 27:287-297.

Kondo, S., J. Sekine, M. Okubo, and Y. Asahida. 1989. The effect of group-size and space allowance on the agonistic and spacing behavior of cattle. Appl. Anim. Behav. Sci. 24:127-135.

Kyntäjä, J., and S. Niskanen. 2007. Milk production, animal recording, dairy advisory services and cattle breeding in Finland. Pages 13-16 in Breeding, Production Recording. Health and the Evaluation of Farm Animals - EAAP 121. Proceedings of the 35th Biennial Session of ICAR, Kuopio, Finland, June 6-10, 2006. Wageningen Academic Publishers, Wageningen, the Netherlands.

Maia, R. P., B. Ask, P. Madsen, J. Pedersen, and R. Labouriau. 2014. Genetic determination of mortality rate in Danish dairy cows: A multivariate competing risk analysis based on the number of survived lactations. J. Dairy Sci. 97:1753-1761.

McConnel, C., J. Lombard, B. Wagner, C. Kopral, and F. Garry. 2015. Herd factors associated with dairy cow mortality. Animal 9:1397-1403.

McConnel, C. S., F. B. Garry, J. E. Lombard, J. A. Kidd, A. E. Hill, and D. H. Gould. 2009. A necropsy-based descriptive study of dairy cow deaths on a Colorado dairy. J. Dairy Sci. 92:1954-1962.

McConnel, C. S., J. E. Lombard, B. A. Wagner, and F. B. Garry. 2008. Evaluation of factors associated with increased dairy cow mortality on United States dairy operations. J. Dairy Sci. 91:1423-1432.

Miller, K., and D. G. M. Woodgush. 1991. Some effects of housing on the social-behavior of dairy-cows. Anim. Prod. 53:271-278.

Miller, R. H., M. T. Kuhn, H. D. Norman, and J. R. Wright. 2008. Death losses for lactating cows in herds enrolled in dairy herd improvement test plans. J. Dairy Sci. 91:3710-3715.

Nielsen, B. H., A. Angelucci, A. Scalvenzi, B. Forkman, F. Fusi, F. Tuyttens, H. Houe, H. Blokhuis, J. T. Sørensen, J. Rothmann, L. Matthews, L. Mounier, L. Bertocchi, M.-M. Richard, M. Donati, P. P. Nielsen, R. Salini, S. de Graaf, S. Hild, S. Messori, S. S. Nielsen, V. Lorenzi, X. Boivin, and P. T. Thomsen. 2014. Use of animal based measures for the assessment of dairy cow welfare ANIBAM. EFSA Support. Publ. 11:EN-659. https://doi.org/10 $.2903 /$ sp.efsa.2014.EN-659

Nørgaard, N. H., K. M. Lind, and J. F. Agger. 1999. Cointegration analysis used in a study of dairy-cow mortality. Prev. Vet. Med. 42:99-119.

Olofsson, J. 1999. Competition for total mixed diets fed for ad libitum intake using one or four cows per feeding station. J. Dairy Sci. 82:69-79.

Olsson, S. O., P. Baekbo, S. O. Hansson, H. Rautala, and O. Osteras. 2001. Disease recording systems and herd health schemes for production diseases. Acta Vet. Scand. Suppl. 94:51-60.

Ospina, P. A., J. A. McArt, T. R. Overton, T. Stokol, and D. V. Nydam. 2013. Using nonesterified fatty acids and $\beta$-hydroxybutyrate concentrations during the transition period for herd-level monitoring of increased risk of disease and decreased reproductive and milking performance. Vet. Clin. North Am. Food Anim. Pract. 29:387-412.

Pinedo, P. J., A. De Vries, and D. W. Webb. 2010. Dynamics of culling risk with disposal codes reported by dairy herd improvement dairy herds. J. Dairy Sci. 93:2250-2261.

Proudfoot, K. L., J. M. Huzzey, and M. A. G. von Keyserlingk. 2009a. The effect of dystocia on the dry matter intake and behavior of Holstein cows. J. Dairy Sci. 92:4937-4944.

Proudfoot, K. L., M. B. Jensen, P. M. H. Heegaard, and M. A. G. von Keyserlingk. 2013. Effect of moving dairy cows at different stages of labor on behavior during parturition. J. Dairy Sci. 96:1638-1646.

Proudfoot, K. L., M. B. Jensen, D. M. Weary, and M. A. G. von Keyserlingk. 2014. Dairy cows seek isolation at calving and when ill. J. Dairy Sci. 97:2731-2739.

Proudfoot, K. L., D. M. Veira, D. M. Weary, and M. A. G. von Keyserlingk. 2009b. Competition at the feed bunk changes the feeding, standing, and social behavior of transition dairy cows. J. Dairy Sci. 92:3116-3123.

Raboisson, D., E. Cahuzac, P. Sans, and G. Allaire. 2011. Herd-level and contextual factors influencing dairy cow mortality in France in 2005 and 2006. J. Dairy Sci. 94:1790-1803.

Sarjokari, K., K. O. Kaustell, T. Hurme, T. Kivinen, O. A. T. Peltoniemi, H. Saloniemi, and P. J. Rajala-Schultz. 2013. Prevalence and risk factors for lameness in insulated free stall barns in Finland. Livest. Sci. 156:44-52.

Schirmann, K., N. Chapinal, D. M. Weary, W. Heuwieser, and M. A. G. von Keyserlingk. 2011. Short-term effects of regrouping on behavior of prepartum dairy cows. J. Dairy Sci. 94:2312-2319.

Shahid, M. Q., J. K. Reneau, H. Chester-Jones, R. C. Chebel, and M. I. Endres. 2015. Cow- and herd-level risk factors for on-farm mortality in Midwest US dairy herds. J. Dairy Sci. 98:4401-4413.

Silanikove, N. 2000. Effects of heat stress on the welfare of extensively managed domestic ruminants. Livest. Prod. Sci. 67:1-18.

Solano, L., H. W. Barkema, E. A. Pajor, S. Mason, S. J. LeBlanc, C. G. R. Nash, D. B. Haley, D. Pellerin, J. Rushen, A. M. de Passillé, E. Vasseur, and K. Orsel. 2016. Associations between lying behavior and lameness in Canadian Holstein-Friesian cows housed in freestall barns. J. Dairy Sci. 99:2086-2101.

Stull, C. L., L. L. M. Messam, C. A. Collar, N. G. Peterson, A. R. Castillo, B. A. Reed, K. L. Andersen, and W. R. VerBoort. 2008. Precipitation and temperature effects on mortality and lactation parameters of dairy cattle in California. J. Dairy Sci. 91:4579-4591.

Telezhenko, E., and C. Bergsten. 2005. Influence of floor type on the locomotion of dairy cows. Appl. Anim. Behav. Sci. 93:183-197.

Thomsen, P. T., K. Dahl-Pedersen, and H. E. Jensen. 2012. Necropsy as a means to gain additional information about causes of dairy cow deaths. J. Dairy Sci. 95:5798-5803.

Thomsen, P. T., and H. Houe. 2006. Dairy cow mortality. A review. Vet. Q. 28:122-129.

Thomsen, P. T., A. M. Kjeldsen, J. T. Sorensen, and H. Houe. 2004. Mortality (including euthanasia) among Danish dairy cows (19902001). Prev. Vet. Med. 62:19-33.

Vaarst, M., and J. T. Sørensen. 2009. Danish dairy farmers' perceptions and attitudes related to calf-management in situations of high versus no calf mortality. Prev. Vet. Med. 89:128-133.

Vitali, A., A. Felici, S. Esposito, U. Bernabucci, L. Bertocchi, C. Maresca, A. Nardone, and N. Lacetera. 2015. The effect of heat waves on dairy cow mortality. J. Dairy Sci. 98:4572-4579.

Vitali, A., M. Segnalini, L. Bertocchi, U. Bernabucci, A. Nardone, and N. Lacetera. 2009. Seasonal pattern of mortality and relationships between mortality and temperature-humidity index in dairy cows. J. Dairy Sci. 92:3781-3790.

Wienke, A. 2011. Frailty Models in Survival Analysis. CRC Press, Boca Raton, FL. 